\title{
Coping by crossdressing: an exploration of exercise clothing for obese heterosexual women
}

\author{
Deborah A. Christel", Nicole H. O’Donnell and Linda Arthur Bradley
}

*Correspondence:
deborah_christel@wsu.edu
Washington State University,
Johnson Hall Annex C-15, PO
BOX 646406, Pullman, WA
99164-6406, USA

99164-6406, USA

\begin{abstract}
Over the past decade participation in physical activity for adult women has decreased while body size has increased. Overweight and obese individuals are considered the majority demographic in the United States; however, plus-sized clothing sales are minimal in comparison to other segments. Furthermore, there is little known about the clothing practices of obese women who engage in physical activity. The current study addresses this research gap by exploring obese heterosexual women's clothing practices for exercise, with an emphasis on what women wear, their perceived choices, alternatives, and satisfaction. Lowe and Anspach's (Home Econ Res J 7(2):121-127, 1978) notion of freedom of dress was the guiding conceptual framework for in-depth interviews with $(n=56)$ obese women. A majority of the women perceived having limited freedom in dress, and reported crossdressing in men's clothing to engage in physical activity, which resulted in a perceived lack of gender expression. Crossdressing is wearing clothing of the opposite sex and gender expression is a way in which a person acts to communicate gender within a given culture. Women in this study indicated and the authors discuss that as clothing size increases, perceived freedom in dress decreases. In order to increase freedom in dress, our participants tended to believe it is their personal responsibility to lose weight.
\end{abstract}

Keywords: Women, Gender, Exercise clothing, Crossdressing, Obesity

\section{Introduction}

Participation in physical activity has dramatically decreased over the past decade, especially among American adult women over the age of 18 (Physical Activity Council Report 2015). The Centers for Disease Control and Prevention (CDC) reports $69.1 \%$ of the population in the United States is considered overweight and within this group, $35.1 \%$ is classified as obese (2015). Consumer reports (Cox 2012) show that over $65 \%$ of women in the US wear plus-size clothing, which is defined as apparel over a US size 14 (Alexander et al. 2012). Prior research supports that weight bias is a barrier to physical activity (Ball et al. 2000; Vartanian and Shaprow 2008). Having desired clothing for exercise can promote physical activity and help obese women overcome weight bias (Lou Watkins et al. 2014). However, there is a lack of research on exercise clothing, especially with regards to the plus-size market.

(C) 2016 Christel et al. This article is distributed under the terms of the Creative Commons Attribution 4.0 International License (http://creativecommons.org/licenses/by/4.0/), which permits unrestricted use, distribution, and reproduction in any medium, provided you give appropriate credit to the original author(s) and the source, provide a link to the Creative Commons license, and indicate if changes were made. 
According to the International ASTM standard table of body measurement, clothing designed for women with a $35.5^{\prime \prime}$ waist circumference correlates to a plus-size 18 (ASTM D6960-04 2004). Plus-size apparel often costs more and is offered in fewer styles, colors, and varieties than apparel in standard sizes (Greenleaf and Kauffung 2015). In turn, plus-size consumers have a difficult time finding outfits that fit well, and many of these women feel excluded and frustrated during shopping experiences (Otieno et al. 2005; Scaraboto and Fischer 2013). Not having appropriate clothing for exercise can lead to further body issue concerns, and the desire to not participate in physical activity (ReddyBest and Harmon 2015). Considering these causes are interrelated, the researchers initiated an inquiry into the exercise clothing needs of obese women.

Preliminary interviews $(n=14)$ were conducted and revealed an unexpected trend of heterosexual obese women wearing men's clothing to engage in physical activity. This finding launched the researchers into exploration of crossdressing, sexuality, thin ideals and exercise clothing. Studies have found that overweight and obese women often feel uncomfortable exercising in public because of the thin ideal that is a part of the workout culture (Vartanian and Shaprow 2008). Fear of being ridiculed by others; inaccessible exercise equipment, clothing and facility limitations have also been found to influence exercise behaviors for obese women (Chambliss et al. 2005). Obese and overweight women are not the only group to experience pressure to be thin. Adding to the complexity of clothing needs, age, sex, and physical activity, sexuality contributes to social pressure for physical attractiveness (Conner et al. 2004). It has been found that heterosexual women and gay men experience more pressure to attain a slender figure than lesbians and heterosexual men (Grogan et al. 2006).

Due to the lack of published research on exercise clothing, this study analyzes what obese heterosexual women wear, their perceived choices, alternatives, and satisfaction in clothing for exercise. As an exploratory study, the authors did not want to limit discussion of exercise clothing to active wear specialty items. Instead, we allowed women to explain what they wear for exercise and thus, we have defined exercise clothing or clothing for exercise as what people wear when engaging in physical activity. To help inform our results, we have conducted literature reviews of plus-size womens' shopping experiences, weight bias, gender identity, crossdressing, appearance, and assumptions about sexuality. Additionally, Lowe and Anspach's classic study on freedom of dress (1973) was used to guide semi-structured, in-depth interviews with $(\mathrm{n}=56)$ heterosexual obese women. The primary investigators outlined four main inquiries for this research a priori using Lowe and Anspach's framework:

1. What do obese women wear for exercise?

2. Do obese women feel they have a choice in their clothing?

3. Do obese women perceive alternatives in their clothing choices?

4. Do obese women experience satisfaction with their clothing choices made?

\section{Literature review}

\section{Plus-size women's clothing experiences}

Research shows evidence for price discrimination, limited clothing choices, and an overall discouraging shopping environment for people who fall outside of standardized mass-market apparel sizes (Chowdhary and Beale 1988; Christel 2014; Colls 2004; Colls and Evans 2014; Kwon and Parham 1994; Peters 2014). The labeling of apparel as 
"plus-size" is often debated and the physical separation of these clothes from the mainstream shopping environment contributes to the othering of fat bodies (Johnson et al. 2004). The CDC (2015) notes that the average US woman has a $37.5^{\prime \prime}$ waist but exercise clothing specialty companies make little or no apparel for larger women. For example, the company Lululemon features its largest sized pants to fit a $32.5^{\prime \prime}$ waist (shop.lululemon.com 2015). Size charts on Nike's website show their XXL sized pants extend to women with 38.5-40.5" waists, however a preliminary search of the clothing available for sale on Nike's website shows few apparel offered in this size-range for women (www. nike.com 2015).

A 2012 industry report reveals that $62 \%$ of plus-size women have a difficult time finding clothes in the styles they want. Additionally, $79 \%$ of plus-size women would like to see clothing styles that are made in smaller sizes to also be offered to the plus-size consumer (Cox 2012). In Peter's (2014) study of fat women's experiences of fashion, one participant explicitly stated that she and her friends shop in the men's department to find pants with longer inseams. In another study, Fowler (1999) found that women shopped for sportswear and exercise clothing in the men's departments because there was more selection accommodating their taste. Tiggeman and Lacey (2009) reveal that large women find shopping for apparel to be a distressing activity.

\section{Weight bias}

Numerous studies have made clear that persons perceived to be overweight or obese are responded to negatively. Jutel (2006) notes that how researchers use the terms overweight and obese has recently shifted. Her meta-analysis of articles in the Pubmed database from 1964-2003 shows the words were originally used in research as descriptors of bodily stature. In the 1990s the terms shifted to signify disease rather than to imply physical size. Jutel argues that discursively denoting overweight and obesity as diseases and "epidemics" (2006, p. 2270) frame fat bodies as non-normative, illness bearing, and in need of pharmaceuticals, clinical monitoring, and/or surgical treatment. Furthermore, defining the term fat solely based on an individual's BMI creates a proposed ingroup and outgroup and Cooper (2010) suggests this devalues fat bodies and places blame on the individual. From this perspective of blame and personal responsibility, the theory of social conduct (Weiner 1995) helps explain how people socially respond to one another and may aid understanding in the root cause of clothing dissatisfaction for obese women.

The theory of social conduct reduces attitudes towards people to either sympathy or anger (Weiner 1995, 2001). Before determining whether anger or sympathy is felt for another person, one must first decide if that person is to be blamed for his/her condition or situation. In the case of the present study, obesity is often thought of as a personal problem and reacted to with anger (Christel 2014). "Anger is an accusation, or value judgment, that follows from the belief that another person could and should have done otherwise" (Weiner 1995, p. 17). On the other hand, sympathy is associated with the lack of responsibility and evokes pity and compassion. These attitudes play a central role in reactions to fat people because most people assume that if is a person is fat, then he or she is lazy (Puhl and Heuer 2009; Puhl et al. 2008). These attitudes stem from a societal belief that people are responsible for all the outcomes of their lives. This type of conduct 
can, potentially, lead to the derogation of any disadvantaged group. To further compound the issue, women experience significantly more stigma and pressure to be thin than do men (Pegoraro et al. 2010; Bordo 2004; Schwartz and Brownell 2004; Chowdhary and Beale 1988). Obesity and stigma are intimately linked to the larger system of social constructs that includes sex, gender, and sexuality.

\section{Gender identity}

Recently academics have worked to differentiate between sex, gender, and sexuality, as these are traditionally binary concepts (Vencato 2013). Most commonly, sex (referring to biology, male or female) has been contrasted with gender (referring to culture expressions of masculinity or femininity). In multiple ways, the body and its differentiating sexual characteristics (such as breasts) become a metaphor for sex (female), where clothing (pink skirt) and its cultural meanings become a metaphor for gender (feminine) (Kaiser 2014, p. 6). Gender is socially constructed in conjunction with other factors of culture such as age, religion, race, ethnicity, body weight, size, and shape.

Gender identity refers to "one's sense of oneself as male, female, or transgender" (American Psychological Association 2010). When one's gender identity and biological sex are not congruent, the individual may identify as transsexual or as another transgender category (Gainor 2000). Gender expression can be defined as the.

"...way in which a person acts to communicate gender within a given culture; for example, in terms of clothing, communication patterns and interests. A person's gender expression may or may not be consistent with socially prescribed gender roles, and may or may not reflect his or her gender identity" (American Psychological Association 2010, p. 28).

http://www.apa.org/pi/lgbt/resources/guidelines.aspx

Butler (1990) refers to gender as a performance of who we are, what we do, and how we participate in an embodied way with culture. From the performative perspective, gender becomes part of the ongoing experiences of fashioning the body. Men and women both wear clothing to modify their appearances and regardless of sex, gender, or sexuality, people have the choice to wear what they desire. Some clothing choices have possible perceived negative social implications and can be associated with stereotypes, sexuality, and may even be considered taboo (Hayfield 2013). The following section addresses the historical context of crossdressing within sex and sexuality research.

\section{Crossdressing}

There are numerous definitions and perspectives with regard to crossdressing. Crossdressing is defined as wearing the clothing of the opposite sex (Vencato 2013). Crossdressing is further defined by Hegland (1999) as, "those occasions when a male puts on feminine dress or a female adopts masculine dress for whatever purpose or to whatever effect" (p. 195). Male to female crossdressing provokes more anxiety than female to male crossdressing, due to the inequality of gendered power relations (Kaiser 2014).

Crossdressing is visible in literature, theatre, history, and the present day with a myriad of uses and reasons. Historically for (white) women, it has often been a means by which to obtain work (Gubar 1981) or enter into war (Wheelwright 1989), circumventing the 
exclusion that barred women from the workplace through disguise (Chesser 2008). In the 20th and 21st centuries in the United States, many women have adopted and worn men's garments in various settings. An example of this is women adopting a masculine style to be accepted in a male-centric workforce, signifying the trickling down of men's professional wear becoming women's professional dress (Cunningham 2005). In athletics, such as in the sport of basketball, women have adopted men's uniforms (Chesser 2008). There has also been a drastic shift in medical uniforms. For example, women nurses used to wear a white dress uniform and, with shifts towards equality, most nurses now wear medical scrubs that were originally designed to fit a male physique (Edwards 2008). Recent history would suggest that crossdressing is rooted in the desire for equality.

Here we see that the acceptability of women wearing men's clothing has changed, as well as the intention for doing so. In the past women have used men's clothing to gain masculine characteristics, even becoming so like a man in appearance that they were hired for men's work or allowed on the battlefield. Within these historical examples, for women, the act of crossdressing carried a level of intentionality. The idea of a female wearing clothing of the opposite sex and the term crossdressing portray a set of cultural connotations. Typically, in these instances, women donned men's clothing to convey a political or cultural statement about gender equality by choice. In the late 20th and 21st centuries, crossdressing has also been used to express individual identity and may or may not have the intention of conveying a political or cultural statement. Therefore, another topic worth addressing is how clothing choices and appearance may lead to assumptions about sexuality.

\section{Appearance and sexuality}

Research has emphasized the significance of clothing and appearance in communicating sexuality and identity in the LGBTQ community. Historically, LGBTQ political and social movements have used dress to both blend in and/or to be visible (Cole 2013). For example, in the 1970s, lesbians were encouraged to reject all aspects of appearance associated with dominant heterosexual femininity (Faderman 1992). The 1980s brought about more adventure and exploration of identities, with labels such as butch and femme. The meanings of these identities have changed throughout recent history and modern scholars (Geczy and Karaminas 2013) discuss identities such as mannish woman, lipstick dykes, designer dykes, androgynous style, and lesbian chic. Dress and appearance have been strong influences in constructing LGBTQ identities. In such, the LGBTQ community respects each individual's freedom to dress as visually or elusively as one desires (Karaminas 2013). "Lesbian dress is a kind of visualization of the limits and limitations of a masculine style" (Geczy and Karaminas 2013, p. 24). Although there is acceptance in exploration of clothing styles and identities within the LGBTQ community (Wilson 2013), scholars have contextualized and categorized specific LGBTQ fashion that is associated with stigma and stereotyping (Hillman and Martin 2002). While the cultural belief of a binary gender system is dissolving, people still expect others' gender associated characteristics to form a consistent package. Crossdressing provides an example of a norm violation and, when stereotyped with LGBTQ sexuality, bias and discrimination may occur (Workman and Freeburg 2009). 
Scholars speculate, "if heterosexual people recognize lesbian and gay sexuality then it is possible that visibility can become vulnerability within the context of the wider society" (Hayfield 2013, p. 17). In other words, those who appear lesbian or gay potentially risk rejection, disapproval, and may be at higher risk of discrimination, hate crimes, and homophobic violence (Eves 2004; Hayfield 2013). To further understand appearance, Hayfield (2013) conducted a study where college students $(\mathrm{n}=36)$ were asked to qualitatively provide appearance norms for lesbians, gay men, and heterosexuals. Students described gay men similar to the way in which mass media represent gay men. Students perceived men who appeared effeminate or 'appearance obsessed' as gay. Students described lesbians as butch and masculine (Hayfield 2013, p. 19), thus providing generalized accounts of how heterosexual individuals perceive and recognize lesbian and gay appearance cues. Heterosexual stereotypes were described as men being masculine and women appearing feminine. Hayfield's study, although small in sample size, provides evidence of how appearance through clothing serves to make sexuality visible (2013). Hayfield's study contributes to our research in providing evidence that clothing greatly offers cues about sexuality, whether or not the individual consciously had that intention. A woman, who may or may not be lesbian, has a chance of being perceived as lesbian if she appears butch or masculine. While some lesbian and bisexuals desire to look authentic in their accounts of clothing and appearance choices (Clarke and Spence 2013), perhaps this desire is not unique to those in the LGBTQ community. An individual's appearance and the messages apparel engender and communicate may not always be those that the wearer wishes to express. "Different articles of clothing do convey different messages, so regardless of the intentions, motivations and level of awareness of the wearer, his/[her] clothes will send a certain message to an observer" (Owyong 2009, p. 195). Research on appearance often starts with an analysis of choice, thus this research is theoretically bound in the concept of freedom in dress.

\section{Conceptual framework}

The concept of freedom in dress, first discussed in 1973 by Lowe and Anspach, proposed three hypotheses based on definitions of freedom. They hypothesized: (1) the feeling of freedom in dress is a state of mind which each person defines for him or herself, (2) there are three phases involved with feeling freedom in dress that include planning, execution of the plan, and enjoyment of the results, and (3) people will feel they are dressed freely when they are rewarded with praise and acceptance (Lowe and Anspach 1973). Lowe and Anspach further explored the freedom in dress concept by examining measureable factors of what leads people to feeling and experiencing freedom in dress (1978). Using the previously developed hypothesis, they examined undergraduate students' 'state of mind' in regards to themselves and freedom in dress. The researchers determined that one's 'state of mind' cannot be concluded without asking the person involved. They determined that people who have freedom in dress experience the following thoughts, (1) they have control over what they wear, (2) they are capable of choosing between available and alternative clothing, and (3) they experience satisfaction with the choices they have made. The study also determined that those who felt less free were likely to feel that way because, (1) of their roles in society, (2) their lack of self-confidence in the clothing choices, and (3) feeling dissatisfied with previous clothing choices. Lowe and 
Buckley conducted the last conceptual study where they examined if freedom and conformity are opposite or simply separate dimensions of dress (1982). Lowe and Buckley concluded that freedom and conformity are separate dimensions and do not predict one another. An individual's choice of clothing was found to be the major component of freedom in dress and experiencing satisfaction is an integral part of freedom (1982).

\section{Methods}

Semi-structured interview questions were developed using findings from Lowe and Anspach $(1973,1978)$ and Lowe and Buckley's research (1982) surrounding the concept of freedom in dress. Topics focused on (1) what types of clothing are worn for exercise, (2) whether women feel they have a choice in their clothing, (3) whether they perceive alternative clothing options for exercise, and (4) whether they experience satisfaction with their clothing choices made for exercise.

\section{Sampling}

Participants were recruited from local community centers, churches, schools, through word of mouth and a flyer posted on an electronic bulletin board. As qualification criteria, participants had to be: (1) female, (2) over the age of 18, (3) residents of the United States, and (4) wear clothing size 14 or higher. Data were collected between 2012 and 2015 totaling a sample size of $n=56$. After the first 14 interviews were conducted the unexpected trend of wearing men's clothing became apparent and the additional interviews were conducted to reach saturation (Saumure and Given 2008). Additionally, the interviewers did not prompt the participants to discuss wearing men's clothing. The interviewers only asked the women to describe what clothing they wore for exercise.

On average, interviews lasted between 60 and $90 \mathrm{~min}$ and were conducted in a private location agreed upon by the participant and researchers. Each interview consisted of a participant, an interviewer, and a note taker. Key observations were discussed with participants during the interview and then summarized by the note taker to aid construct validity (Smith 2015). Conversations were audio recorded and participants' identifying information was separated from all data.

\section{Content coding}

All interviews were transcribed and added to a master document with a total of 151 pages of single spaced text. The unit of analysis was each response paragraph with a total of 1057 responses, and an average of seven per page. Three coders independently analyzed $20 \%$ of the sample ( $\mathrm{n}=30$ pages) to achieve intercoder reliability. The pages analyzed for intercoder reliability were chosen via an Excel random number generator. The content was first coded according to the four general inquiries of the study. The percentages within the results section are based on codes in each theme for the response paragraph unit of analysis. For example, $62 \%$ of coded responses for the perceived alternatives category were coded as no and $38 \%$ were coded as yes. Each of the following code descriptions include the Krippendorff's (2011) alpha reliability statistics of agreement between the categories. Responses for what women wear for exercise were coded as (1) women's clothing $(\alpha=0.858)$ and (2) men's clothing $(\alpha=0.903)$. Perceived choice was coded as (3) yes $(\alpha=0.887)$ and $(4)$ no $(\alpha=0.878)$. Knowledge and perceptions 
of alternatives were coded as (5) yes $(\alpha=0.870)$ and $(6)$ no $(\alpha=0.849)$. Additionally, whether women experience satisfaction with exercise clothing was coded as (7) yes $(\alpha=0.836)$ and $(8)$ no $(\alpha=0.875)$. When coding what women wear for exercise, the researchers noted that a category for unisex would need to be added. The codebook was adapted and (9) unisex clothing was added to the final codebook. Once coding was complete, the primary investigators met to discuss and reach consensus on the themes present under each code.

\section{Results and discussion}

The results presented in this section encompass the experiences of exercise clothing worn by obese heterosexual women. For purposes of clarity, the results are organized into: demographics, what clothing women wear for exercise, their perceived choices, and their perceived alternatives of clothing choices. Lastly, satisfaction and dissatisfaction of exercise clothing is presented.

\section{Demographics}

Table 1 provides a summary of the $(n=56)$ participants' demographics. The participants ranged in age from 20-72 (Mean age $=43)$, clothing size was reported as $L / 14(\mathrm{n}=14)$, $\mathrm{XL} / 16(\mathrm{n}=15), 2 \mathrm{X} / 18(\mathrm{n}=10), 3 \mathrm{X} / 20(\mathrm{n}=13)$ and $4 \mathrm{X} / 22(\mathrm{n}=4)$ with an average clothing size of 2XL. The ethnicity of participants was as follows: Caucasian $(\mathrm{n}=30)$, Middle Eastern $(\mathrm{n}=10)$, African American $(\mathrm{n}=10)$, Hispanic/Mexican $(\mathrm{n}=5)$, and Asian $(\mathrm{n}=1)$. Participants reported a range of household incomes, from $\$ 16,000$ per year up to $\$ 150,000$ per year. When asked for relationship status, women identified as

Table 1 Demographic profile of participants $(n=56)$

\begin{tabular}{ll}
\hline Measure & Sample data \\
\hline Age & $20-29(n=4)$ \\
& $30-39(n=19)$ \\
& $40-49(n=14)$ \\
& $50-59(n=10)$ \\
Clothing Size & $60+(n=9)$ \\
& L/14 $(n=14)$ \\
& XL/16 $(n=15)$ \\
Ethnicity & $2 X / 18(n=10)$ \\
& $3 X / 20(n=13)$ \\
& $4 X / 22(n=4)$ \\
Annual income & Caucasian $(n=30)$ \\
Marital status & Middle Eastern $(n=10)$ \\
& African American $(n=10)$ \\
& Hispanic/Mexican $(n=5)$ \\
& Asian $(n=1)$ \\
& $\$ 16,000-\$ 150,000(n=56)$ \\
\hline Annul $(n=36)$
\end{tabular}

a Annual income was reported as individual income 
married $(n=36)$, single $(n=16)$, divorced $(n=3)$, and widowed $(n=1)$. A majority $(87.5 \%)$ of the sample lived in the Pacific Northwest of the United States.

\section{Clothing worn for exercise}

Clothing discussion related to menswear accounted for $37 \%$ of coded responses. The researchers coded responses as 'men's clothing' if the participant specifically used one of the following prefixes before discussing apparel: men's, boys, husbands, sons, boyfriends, guys, and/or male. Discussion of women's clothing accounted for $29 \%$ of coded responses. Women's clothing was coded when the following terms were used: women's, girls, and female. Unisex clothing discussion accounted for $34 \%$ of coded responses. Because participants were not specifically asked about female and male clothing, there were numerous times throughout the data in which women spoke of wearing clothes for exercise without designating if the clothes were sex-specific. The following types of statements were coded as unisex in response to the question, what do you wear for exercise?

Claire (31 years old): I have my capris and umm t-shirts usually... one of my free fun run t-shirts.

Darlene (48 years old): The $t$-shirts I wear are regular cotton that you get from the blood drive mobile free t-shirts thing, nothing special, unisex.

If a participant stated that they wore a free and/or cotton $t$-shirt from an event, the researchers deemed that as a unisex garment. Also, if the participants specified unisex, that was coded as unisex. The following statements are some examples of how women described their clothing for exercise.

Tia (46 years old): So I wear my husband's $t$-shirts a lot and then I put it on and then I fold it up over my elbows and then I go like this (pushes away from body with arms in swinging motion) until the bottom is bigger so it will not be, like, super tight so the shoulders fit but the bottom is all weird. My husband is like, 'quit stretching all my shirts out!'

Claire (31 years old): The bottoms are too short a lot of the times so I wear my husband's basketball shorts with my tankini a lot. I want something that long and not too tight so they're super ratty but yeah, that's the only bathing suit I've ever felt comfortable in public, my husband's basketball shorts.

April (59 years old): Umm, let's see, some sweat pants or capris stretch pants and just like a $t$-shirt.

Carla (55 years old): So I wear a pair of, I guess they'd be like, capris. They're just pull-on stretchy pants an extra size up because I like them to be comfortable. I don't want them to be tight.

Carla (55 years old): I borrow my husband's [clothes]. My son's too, he's a big guy so I'll take his old $t$-shirts off his hands. 
Roberta: (41 years old): When you have large thighs it pulls the inseam up in your crotch, so I often buy men's shorts because they are longer and closer to my knee.

Roberta (41 years old): Men's basketball shorts, Target has got the best ones that are easily 8 or 9"es long and that is in the summer when it is cool enough, and in the winter I wear athletic pants. On tops, I don't like a lot of women's athletic wear, they have cap sleeves and I like mine down to my elbow so I just wear men's or unisex $t$-shirts.

These comments represent how obese women dress for exercise. The main items mentioned were capris, yoga pants, basketball shorts, and cotton $\mathrm{t}$-shirts. Several women mentioned wearing men's basketball shorts because of the length, sweat pants for the additional length in the rise, and cotton knit capris. These were typically worn in combination with a cotton $t$-shirt. This was also found in previous studies where women purchased menswear because the pants had longer inseams and menswear provided more selection accommodating their needs (Peters 2014; Fowler 1999).

\section{Freedom in dress: choice}

Choice was coded as perceived control (Lowe and Buckley 1982) over what exercise clothing are purchased and worn in relation to one's desired functional, aesthetic, and expressive needs. Analysis reveals that $81 \%$ of coded responses, a majority of participants, do not feel they have a choice in what they wear. The following quotes illustrate this sentiment.

Brenda (43 years old): In the past, the pants would be extremely loose because I was buying a men's $4 x$. So, it was cut to fit a man and it was too big. Actually all the workout tops that I found at my regular stores (Target and Big Dog), I found several men's polyester shirts but not female. They [men's] were the only ones that fit all around.

Anna Lee (27 years old): I mentioned that I often buy men's clothing. I have a mix right now, but I would say that $50 \%$ of my wardrobe is from the men's section because I like tops to be baggier so it is easier to find clothes that fit [in the men's section]. But, men's clothes come in dark colors that are often hotter in the sun. So when I can find women's clothing that fit, I enjoy brighter colors because I don't always have that option.... If I could find what I wanted in women's section then I would stop shopping in the men's section.

Kris (61 years old): As a larger woman, I tend to be round and full. I'm not flat and bony. I wear men's pants all the time... The waistbands are always covered with some elastic and they also have a string to $c^{\prime \prime}$ them in at the waist if I need. I never find them binding. I do envy some of the women's pants that have a flat waist, though. However, I find most of those are cut low, which is fine for a much smaller woman with a flat waist but the rest of us can't wear that.

Lucia (46 years old): You instead look for clothes that don't make you look so fat. I mean, for example I don't use stripes, striped clothes or with square patterns, 
because I'm going to look like a ball.

Judy (31 years old): Clothing choices aren't always pleasant for the very plus-sized like 4-6× which is where I was at 2 years ago and, I remember people looking at me when I was in the men's section feeling like I didn't belong. The slimmer I get the less I think about it because I'm so excited about the weight-loss, but every once in a while I still feel like a bit of a freak show.

Ashley (22 years old.): I just want to be the best version of me and it's hard. When you see a dress that you want but it's a size two and you won't fit, it makes you want to lose that weight and fit it so you can have that dress especially with people around you when you shop with people of different sizes and they can buy what you can't buy and you don't have the same option. It's hard because then it makes you think maybe I should change my body, maybe I should change the way I look so I can get these things.

Only a small portion, $19 \%$ of coded responses, mentioned that they felt they had freedom in choice. When women perceived choice, they often cited brand patronage and how future weight loss will lead to freedom in choice. The following quotes were coded as feeling freedom in choice and illustrate the different perspectives. While the participants might not be entirely satisfied with the clothing options, they do express to some degree, freedom in choice of clothing.

Wendy (33 years old): I mean it is not hard to find [exercise clothes] I guess I can shop in the normal stores. Ummm. I only wear a $1 \times$ so I don't have a hard time finding things. I got my last pants at Khols.

Becca (25 years old): Christopher Banks, there's more clothes. I'm kind of shocked. I'm like finally a place where they have sizes, variety, and color. I didn't know about them until the mall here... I find they have selection.

Janet (45 years old): Sometimes Lane Bryant gets it right. They keep the styles really trendy and attractive and it doesn't look like a Florida resort with a big giant print. But sometimes it is just once a woman reaches a certain size, designers think she doesn't care what she looks like and that is not true.

Lynne (31 years old): Just the fact that I know the smaller I get the more options I have and right now there are not a lot of options for plus-size clothes and it is really discouraging honestly. I have gotten to the point where I am buying shirts to layering them so when I am moving a certain way I am not showing my stomach or umm. I have a really long torso and so I have a really hard time finding shirts long enough or pants... The biggest encouragement is the smaller I get I will have more options.

Jessica (33 years): I like to try things on and I would just do men's $2 \times$ for $t$-shirts and they never fit right but it is one of those things that you give to get. 


\section{Freedom in dress: perceived alternatives}

A total of $62 \%$ of coded responses revealed a perceived lack of alternative choices in exercise clothing, while $38 \%$ of responses perceived alternatives available. Alternative choices were coded for comments that either clearly demonstrated knowledge of other options for exercise clothing or no expression in awareness of alternative clothing options. The following statements exemplify those who did not perceive any alternatives.

Janet (45 years old): I think it is why often times I'll just go with some ratty pair of sweats I know I already have at home instead of trying to find new clothes because it is an exercise in frustration. I never, rarely have I been able to just walk into a store and go, oh I know that will fit because I have had these before.

Nina (43 years old): For a long time it was very difficult but once I started shopping in the men's section I find the bottoms that are fine. It's very limited because I would like clothes that are more feminine, like the skort, but I simply can't find one.

Claire (31 years old): There is not the selection that you want, and the clothes get uglier the bigger you get, and there might be cute clothes for smaller girls, but at the store the plus-size selection gets smaller and uglier.

Marie (27 years old): My whole time looking for exercise clothing I have found one pair of pants that I like so I have for the most part just given up and I will go and raid my dad's closet.

The following statements exemplify participants who did perceive clothing alternatives. Consistently mentioned by participants was shopping online for feminine exercise clothing. While online shopping wasn't a desirable alternative for women, women perceived online shopping as an alternative.

Claire (31 years old): Probably $90 \%$ of everything I wear I get online because there's nowhere to try it on here, and that brings in the issue of being on the higher end of the plus-size scale.

Darlene (48 years old): It's also a time thing, if I can find something. I think I've bought most of my clothes online lately. The thought of going out and shopping is just depressing.

Lucia (46 years old): You have to be a size small, extra-small, or medium to find what you want in the store, because there is not a large size. Then you are limited, but here, in the United States, there is everything, and if you do not find in the store, you find online. That's great.

\section{Freedom in dress: satisfaction and dissatisfaction}

Satisfaction was coded as being content with the clothing selected, purchased, and worn for exercise. Only $18 \%$ of coded responses expressed satisfaction with exercise clothing. In turn, $82 \%$ of our responses were coded as experiencing dissatisfaction with exercise 
clothing selected. Here are some examples of participants who expressed satisfaction with clothing.

Darlene (48 years old): Well just that in high-intensity workouts, and expense too, I mean. So I got my Title 9 catalog, just came in, and so I would like something new. I think what I have is a Champion one that's worked pretty well.

April (59 years old): It is nice to have new clothes every once and a while and I really like the color of this one shirt, it's like an aqua blue and it picks you up a little.

Dissatisfaction with clothing purchased was reported in $82 \%$ of responses coded. The most common response throughout the transcript was expression of dissatisfaction with clothing selected, purchased, and worn. The responses of dissatisfaction inherently linked back to how clothing made the women feel emotionally as well as how they felt physically while wearing the clothes.

Brenda (43 years old): Men's clothing make me feel fat and dumpy. They do not make me feel nice or put together or, you know what I mean, but I just needed clothing that fit the need at that time.

Mariam (35 years old): I need to get in shape and I promised myself that I would not shop for clothes until I absolutely had to, like I was definitely down a size then I would treat myself to a new workout outfit and a pair of jeans.

Sue (69 years old): Yeah, even like some of the women t-shirts, I feel sloppy. How clothes fit and how they feel on is more important to me, so more than you may think...It is a challenge with a shirt to be not too long that it's sloppy but that when you sit down it's long enough to cover up in the back.

Betty (58 years. old): I have to work out so I push the clothing aside and wear what goes around my body. I think people are trying not to judge but are kind of not able to help it you know, and clothing does play a role in that like if you are wearing things that are too small or revealing, it's going to draw attention to you and that is not what you really want when you go to the gym because I'm already fat, so I wear the dark colored men's clothing to try not and stand out as much as I might in the ladies pink stuff. Even though I love the color pink just not at the gym.

Tara (30 years old): I'm realizing my clothes aren't fitting all the time so I want to lose weight.

Lucia (46 years old): You use rather dark colors and things that instead of having darts or things like that, that instead of looking good, ruins your figure. You use something more discreet, because ultimately, when you are overweight, nothing favors you, but at least you try to not look worse than you are. That is the real thing, not complicated, real. 


\section{Conclusion}

The women in our sample reveal that it feels nearly impossible to be obese and feminine especially in the realm of exercise clothing. We identified two main themes in the data: (1) no freedom in dress and (2) weight loss is the only solution to express feminine gender. These themes represent two different ways of understanding the concepts of the fat body and exercise clothing. First, as the body gets larger the freedom to dress femininely is reduced, and second, obese heterosexual women believe they need to lose weight and will have more feminine exercise clothing options once they do. Until then, they will cope by crossdressing.

\section{No freedom in dress}

According the conceptual framework of Lowe and Anspach's (1978) freedom in dress, most obese heterosexual women do not perceive alternative exercise clothing choices and thus they are not able to make successful clothing choices. Our findings continue to confirm previous studies where larger women perceive there to be limited clothing choices (Chowdhary and Beale 1988; Colls 2004; Colls and Evans 2014; Christel 2014; Kwon and Parham 1994; Peters 2014).

Without perceived choice and alternatives, some women resorted to crossdressing. Additionally, smaller women's clothing available for exercise was perceived by participants as sexualized. Comments illustrate how dissatisfied the women were with the tightness of exercise clothing. Participants specifically noted not wanting to draw attention to their bodies, so in turn men's clothing was donned because men's clothing better conceals the body and helps one camouflage. The participants wanted feminine expression without sexualization. The perceived message from the fashion industry is that in order to publicly exercise, one must be sexualized and wear revealing, tight clothing. Both a societal pressure for attractiveness (Conner et al. 2004) and feelings of needing to conform to the thin ideal (Vartanian and Shaprow 2008) were realized by many of the women. However, these pressures did not stop our women from exercising, rather they wore men's clothing as a way to exercise in public.

Based on current definitions of crossdressing (Vencato 2013; Hegland 1999), our sample is engaging in this practice. Crossdressing can also be viewed as a performance to subvert the gendered binary boundaries (Kaiser 2014). Though, the heterosexual women in our study did not want to crossdress or in any way challenge the hegemonic gendered system. The issue here is that if the participants wanted to be physically active, they felt they had no other choice than to wear men's clothing. With some clothing items, it is acceptable for women to wear jeans and blazers that are typically associated with masculinity but are considered in context related to fit, shape, accessories and other social cues. Considering this, female to male crossdressing might not seem as controversial. As gender expression includes all appearances and bodily behaviors, obese heterosexual women's gender expression in exercise clothing is compromised. For example, although not encouraged in exercise culture, women still have the option to wear feminine hairstyles, makeup, and accessories, but the choice and alternatives in feminine exercise clothing is perceived as limited.

We can deduce that a heterosexual woman with limited feminine exercise apparel may be perceived as lesbian if she wears masculine clothing. While appearing lesbian itself is 
not problematic, if the wearer does not want to be identified as such, then as we see in our results, sexual identity through clothing is also negotiated. Previous literature suggests that obese women, "by not conforming to an expectation of slenderness are in the margins of femininity" (Adam 2001, p. 41). The cultural meanings associated with tightfitted clothing have become a metaphor for femininity. When considering the factors of obesity and a desire to dress in feminine exercise clothing, our sample suggests that the ability to express desired gender through clothing is non-existent.

There seems to be little doubt that gender and clothing norms are undergoing a significant change. In the 21st century, individuals in Western societies have agency to define and express gender, sex, sexuality, and/or appearance in any way one desires. A woman is lesbian, gay, or bisexual because she says she is (Faderman 1992). Given the increasingly gender-fluidity in fashion (Diderich 2015) and the growing acceptance of sex, gender, and sexuality as a continuum, the authors contemplate the restrictions of the term crossdressing. For the term and use of crossdressing is part of an outdated binary system that segregates sex and gender, and doesn't serve to broaden acceptance of exploration in appearance.

The use of the word crossdressing is perhaps antiquated in that a person's gender, gender identity, gender expression, sexuality, and with modern medicine, sex, can be defined, re-defined, and changed and expressed in whatever way an individual desires. Gainor (2000) suggests that when one's gender identity and biological sex are not congruent, the individual may identify as transsexual or as another transgender category. Fashion has become more gender fluid and individual expression is valued in the $21^{\text {st }}$ century (Faderman 1992). As individuals have the choice to use language they desire to identify themselves, the authors examine the definitions of crossdressing and how that applies to obese heterosexual women. Crossdressing is wearing the clothing of the opposite sex (Vencato 2013), or, "those occasions when a male puts on feminine dress or a female adopts masculine dress for whatever purpose or to whatever effect" (Hegland 1999, p. 195). These definitions of crossdressing preserve the binary system and fail to address current negotiations related to fashion and the body for the LGBTQ community and people of size. Our study finds that obese heterosexual women are limited in their clothing choices and do not have equal opportunity to express their identity in the way they desire.

There is privilege accompanying a thin body (Bacon 2010) and regardless of gender, sex, sexuality, and/or appearance, obese people are limited and oppressed in their options to express gender through clothing. Therefore, when clothing is not available for people, they resort to what is available whether or not it is reflective of the individuality they desire to express. Limitations in clothing for obese people imposition their ability to explore identities. From that perspective, the authors conclude that the term crossdressing can only apply to those who classify themselves in a binary sex and gender system and are able to find the clothing size needed to cross to the other gender.

Therefore, if there were more freedom in dress (Lowe and Anspach 1978), perhaps obese women might freely choose to wear men's exercise clothing but without the choice, they feel marginalized and constrained to, at some degree, express masculine gender. While none of the participants said they felt others might perceived them as part of the LGBTQ community, they did feel marginalized. Limitations in feminine exercise clothing for obese women can be seen as form of social rejection. The social 
consequences of crossdressing mean individuals who identify as female and desire to express feminine gender are unable to and are perhaps stereotyped based on their clothing (Hayfield 2013). As suggested, some individuals make assumptions about the dress of others, including the LGBTQ community, who may appear outside the sexuality norms and they risk rejection, disapproval, and may be at higher risk of discrimination (Eves 2004; Hayfield 2013).

\section{The only solution to express feminine gender is through weight loss}

One of the most striking outcomes of the data was the emphasis on how women look forward to being able to wearing smaller sized clothing and will have more options once they lose weight. This research confirms Lowe and Anspach's (1978) findings that lack in freedom of dress can be a result of one's role in society. As obese women, our participants felt they were at fault for not having choices or alternatives in exercise clothing.

Women were not satisfied with wearing men's clothing for exercise; however, they took responsibility for wearing men's clothing and did not express any anger in their reduced freedom in dress and by default their need to crossdress. In other words, while women stated a desire for alternatives, it is speculated that they ultimately believe it is their fault they are overweight/obese and they felt that until they lost weight and became a culturally appropriate size for a heterosexual female/woman, they would wear men's apparel. The theory of social conduct would predict that obese people are blamed for their condition and as a result are treated with anger, blame, and social rejection (Weiner 1995, 2001). It seems our sample feels that blame and social rejection can only be solved by losing weight. While they have a lack of self-confidence in clothing choices (Lowe and Anspach 1978), they seem to feel that once they lose weight, they will be rewarded with deserible alternative options and they will be able to join the 'deserving' group that falls within the acceptable/non-deviant body size and then have the freedom to express feminine gender.

\section{Implications and future research}

The women in our sample identified their sex as female and expressed desire to wear feminine clothing for exercise. Past research found that women shopped in men's clothing sections based on clothing taste (Fowler 1999). Our results reveal that obese heterosexual women see purchasing and wearing men's clothing as an undesired alternative. A common reason for wearing men's clothing discussed by our participants was due to the tightness of women's garments. An implication of this finding is the need to reconsider the sizing, functionality, and overall design of feminine exercise clothing. Another consideration is the prevalence of internalization and self-blame of being overweight or obese. Future studies should consider how clothing evokes these emotions and perhaps impact other areas of life.

From a retail perspective, plus-size exercise clothing can be analyzed through a comparative analysis of women's online versus in store purchasing habits. This research examined what clothing women wear for exercise and their satisfaction/dissatisfaction with these garments. A central focus on purchasing motivations and consumer behaviors merits further attention. 
There are still ongoing debates that require multidisciplinary studies to understand complexities within and across clothing contexts. The concepts of sex, gender, and sexuality are intertwined with fashion, dress and clothing and interdisciplinary research is needed. Further exploration of the word crossdressing could be of interest and value to many disciplines. Clothing practices of obese women and exercise adherence or motivation could also be of further interest. Specifically, studies could explore clothing practices and identity negotiations that exist within obese and LGBTQ communities. Exploring sexual orientation, body weight, clothing, and freedom in dress are future suggestions.

A significant implication of this research is, regardless of body weight, shape, or size; all individuals should have access to clothing to support leading an active lifestyle. By not having access to desirable exercise clothing, obese heterosexual women are at a disadvantage. The authors suggest the fashion industry and academia incorporate more opportunities to learn about plus-size, overweight, and obese body shapes. In doing this, we hope that higher quality and increased quantity of alternative clothing will become available to those who currently experience less freedom in dress. As the market segment continues to grow, it would greatly behoove the industry to consider the wants and needs of plus-sized women's exercise clothing. Therefore, the fashion industry should reevaluate the availability of plus-size exercise clothing and work towards creating an equally inclusive environment for consumers.

\section{Authors' contributions}

DAC conducted initial interviews. DAC and NHO developed the literature review and conceptual approach to second round of data collection. $\mathrm{NHO}$ and $\mathrm{LAB}$ conducted second round of interviews. DAC and NHO transcribed interviews, coded, and analyzed data. DAC, $\mathrm{NHO}$ and $\mathrm{LAB}$ guided the analysis of the results and conclusions and all contributed to the formatting and editing of the manuscript. All authors read and approved the final manuscript.

Competing interests

The authors declare that they have no competing interests.

Received: 11 June 2015 Accepted: 8 April 2016

Published online: 25 May 2016

\section{References}

Adam, A. (2001). Big girls' blouses: Learning to live with polyester. In A. Guy, E. Green, \& M. Banim (Eds.), Through the wardrobe: women's relationships with their clothes (pp. 39-53). Oxford: Berg Publishers.

Alexander, M., Pisut, G. R., \& Ivanescu, A. (2012). Investigating women's plus-size body measurements and hip shape variation based on size USA data. International Journal of Fashion Design, Technology and Education, 5(1), 3-12.

American Psychological Association. (2010). Publication Manual of the American Psychological Association (6th ed.). Boston: Wadsworth Cengage Learning.

ASTM D6960-04. (2004). Standard table of body measurements relating to women's plus size figure types, size 14 W-32 W (Withdrawn 2013). ASTM International, West Conshohocken, PA. doi:10.1520/D6960-04.

Bacon, L. (2010). Health at every size: The surprising truth about your weight. Dallas: BenBella Books.

Ball, K., Crawford, D., \& Owen, N. (2000). Obesity as a barrier to physical activity. Australian and New Zealand Journal of Public Health, 24(3), 331-333.

Bordo, S. (2004). Unbearable weight. New York: Random House.

Butler, J. (1990). Gender trouble. Florence: Taylor and Francis.

Centers for Disease Control and Prevention. (2015). Obesity Statistics.

Chambliss, H. O., Blair, S. N., Brownell, K. D., Puhl, R. M., Schwartz, M. B., \& Rudd, L. (2005). Improving the fitness landscape. In K. D. Brownell, R. M. Puhl, M. B. Schwarts, \& L. Rudd (Eds.), Weight bias: Nature, consequences, and remedies (pp. 248-264). New York: Guilford Press.

Chesser, L. (2008). 'Woman in a suit of male': sexuality, race and the woman worker in male 'disguise', 1890-1920. Australian Feminist Studies, 23, 175-194.

Chowdhary, U., \& Beale, N. V. (1988). Plus-size women's clothing interest, satisfactions and dissatisfactions with ready-towear apparel. Perceptual and Motor Skills, 66, 783-788.

Christel, D. A. (2014). It's your fault you're fat: Judgments of responsibility and social conduct in the fashion industry. Clothing Cultures, 1(3), 293-310. 
Clarke, V., \& Spence, K. (2013).' I am who I am'? Navigating norms and the importance of authenticity in lesbian and bisexual women's accounts of their appearance practices. Psychology and Sexuality, 4(1), 25-33.

Cole, S. (2013). Queerly visible: Gay men, dress, and style 1960-2012. In V. Steele (Ed.), A queer history of fashion: from the closet to the catwalk (pp. 135-165). New York: Fashion Institute of Technology New York.

Colls, R. (2004). 'Looking alright, feeling alright': Emotions, sizing and the geographies of women's experiences of clothing consumption. Social and Cultural Geography, 5, 583-596.

Colls, R., \& Evans, B. (2014). Making space for fat bodies?: A critical account of 'the obesogenic environment'. Progress in Human Geography, 38, 733-753.

Conner, M., Johnson, C., \& Grogan, S. (2004). Gender, sexuality, body image and eating behaviours. Journal of Health Psychology, 9(4), 505-515.

Cooper, C. (2010). Fat studies: Mapping the field. Sociology Compass, 4(12), 1020-1034.

Cox, M. (2012). NPD Group reports size matters to American women. The NPD Group. Retrieved from https://www.npd. com/wps/portal/npd/us/news/press-releases/pr_120910/.

Cunningham, P. A. (2005). Dressing for success: The re-suiting of corporate America in the 1970s. In L. Welters \& P. A. Cunningham (Eds.), Twentieth-century American fashion (pp. 191-208). New York: Berg Publishers.

Diderich, J. (2015). The millennial customers' acceptance of gender non-conformity is having a dramatic impact on fashion. Women's Wear Daily, 4, 48-50.

Edwards, S. (2008). Scrubs-style uniforms will erode nurses' identity. Nursing Standard, 23(11), 32-33.

Eves, A. (2004). Queer theory, butch/femme identities and lesbian space. Sexualities, 7(4), 480-496.

Faderman, L. (1992). The return of butch and femme: A phenomenon in lesbian sexuality of the 1980s and 1990s. Journal of the History of Sexuality., 2(4), 578-596.

Fowler, D. (1999). The attributes sought in sports apparel: a ranking. Journal of Marketing, Theory and Practice., 7(4), 81-88.

Gainor, K. A. (2000). Including transgender issues in lesbian, gay and bisexual psychology. Education, Research, And Practice in Lesbian, Gay, Bisexual, And Transgendered Psychology: A Resource Manual, 5, 131-160.

Geczy, A., \& Karaminas, V. (2013). Queer style (pp. 1-45). New York: Bloomsbury.

Greenleaf, C., \& Kauffung, A. (2015). Exploratory online market analysis of plus-size and regular-size exercise clothing. Research Quarterly for Exercise and Sport, 86, A96-A96.

Grogan, S., Conner, M., \& Smithson, H. (2006). Sexuality and exercise motivations: Are gay men and heterosexual women most likely to be motivated by concern about weight and appearance? Sex Roles, 55(7-8), 567-572.

Gubar, S. (1981). Blessings in disguise: Crossdressing and re-dressing for female modernists. The Massachusetts Review, 22, 477-508.

Hayfield, N. (2013). 'Never judge a book by its cover?': Students' understandings of lesbian, gay and bisexual appearance. Psychology and Sexuality, 4(1), 16-24.

Hegland, J. (1999). Drag queens, transvestites, transsexuals: Stepping across the accepted boundaries of gender. In M. L. Damhorst, K. A. Miller, \& S. O. Michelman (Eds.), The Meanings of Dress (pp. 193-205). New York: Fairchild.

Hillman, J., \& Martin, R. A. (2002). Lessons about gay and lesbian lives: A spaceship exercise. Teaching of Psychology, 29(4), 308-311.

Johnson, J. L., Bottorff, J. L., Browne, A. J., Grewal, S., Hilton, B. A., \& Clarke, H. (2004). Othering and being othered in the context of health care services. Health Communication, 16(2), 255-271.

Jutel, A. (2006). The emergence of overweight as a disease entity: Measuring up normality. Social Science and Medicine, 63(9), 2268-2276.

Kaiser, S. (2014). Gendering fashion, fashioning gender: beyond binaries. In S. Kaiser (Ed.), Fashion and Cultural Studies (pp. 121-170). New York: Bloomsbury.

Karaminas, V. (2013). Born this way: Lesbian style since the eighties. In V. Steele (Ed.), A Queer History of Fashion: From the Closet to the Catwalk (pp. 193-216). New York: Fashion Institute of Technology New York.

Krippendorff, K. (2011). Agreement and information in the reliability of coding. Communication Methods and Measures, $5(2), 93-112$.

Kwon, Y. H., \& Parham, E. S. (1994). Effects of state of fatness perception on weight conscious women's clothing practices. Clothing and Textiles Research Journal, 12(4), 16-21.

Lou Watkins, P., Ebbeck, V., \& Levy, S. (2014). Overcoming weight bias: promoting physical activity and psychosocial health. Ethnicity and Inequalities in Health and Social Care, 7(4), 187-197.

Lowe, E. D., \& Anspach, K. A. (1973). Toward a definition of freedom in dress. Family and Consumer Sciences Research Journal, 1(4), 246-250.

Lowe, E. D., \& Anspach, K. A. (1978). Freedom of dress: A search for related factors. Home Economics Research Journal, 7(2), $121-127$.

Lowe, E. D., \& Buckley, H. M. (1982). Freedom and conformity in dress: A two-dimensional approach. Home Economics Research Journal, 11(2), 197-204.

Otieno, R., Harrow, C., \& Lea-Greenwood, G. (2005). The unhappy shopper, a retail experience: Exploring fashion, fit and affordability. International Journal of Retail and Distribution Management, 33(4), 298-309.

Owyong, Y. S. M. (2009). Clothing semiotics and the social construction of power relations. Social Semiotics, 19(2), $191-211$.

Pegoraro, A., Ayer, S., \& O'Reilly, N. (2010). Consumer consumption and advertising through sport. American Behavioral Scientist, 53(10), 1454-1475.

Peters, L. D. (2014). You are what you wear: How plus-size fashion figures in fat identity formation. Fashion Theory, 18, $45-72$.

Physical Activity Council. (2015). The 2015 participation report. Sports Marketing Services USA. Retrieved from http:// fliphtml5.com/ogoc/bvnn/basic.

Puhl, R. M., Andreyeva, T., \& Brownell, K. D. (2008). Perceptions of weight discrimination: Prevalence and comparison to race and gender discrimination in America. International Journal of Obesity, 32(6), 992-1000.

Puhl, R. M., \& Heuer, C. A. (2009). The stigma of obesity: A review and update. Obesity, 17(5), 941-964. 
Reddy-Best, K. L., \& Harmon, J. (2015). Overweight boy's and girl's experiences with and perception of athletic clothing and its relationship to physical activity participation. Fashion and Textiles, 2(1), 1-16.

Saumure, K., \& Given, L. (2008). Data saturation. In M. Lisa (Ed.), The Sage Encyclopedia of Qualitative Research Methods (pp. 196-197). Thousand Oaks: Sage Publications. doi:10.4135/9781412963909.n99.

Scaraboto, D., \& Fischer, E. (2013). Frustrated fatshionistas: An institutional theory perspective on consumer quests for greater choice in mainstream markets. Journal of Consumer Research, 39(6), 1234-1257.

Schwartz, M. B., \& Brownell, K. D. (2004). Obesity and body image. Body Image, 1(1), 43-56.

Smith, J. A. (Ed.). (2015). Qualitative psychology: A practical guide to research methods. Thousand Oaks: Sage Publications. Tiggemann, M., \& Lacey, C. (2009). Shopping for clothes: Body satisfaction, appearance investment, and functions of clothing among female shoppers. Body Image, 6, 285-291.

Vartanian, L. R., \& Shaprow, J. G. (2008). Effects of weight stigma on exercise motivation and behavior a preliminary investigation among college-aged females. Journal of Health Psychology, 13(1), 131-138.

Vencato, A. P. (2013). Body, gender, sexuality and subjectivity among men who practice crossdressing. In: H. Sívori (Ed.) Sexuality, Culture and Politics - A South American Reader (pp. 346-365). Retrieved from http://www.clam.org.br/ uploads/publicacoes/book2/cover.pdf.

Weiner, B. (1995). Judgments of responsibility: A foundation for a theory of social conduct. New York: Guilford Press.

Weiner, B. (2001). Intrapersonal and interpersonal theories of motivation from an attribution perspective. In F. Salili, C. Chiu, \& Y. Hong (Eds.), Student Motivation (pp. 17-30). New York: Kluwer Academic.

Wheelwright, J. (1989). Amazons and military maids: Women who dressed as men in the pursuit of life, liberty and happiness. Great Britain: Pandora Press.

Wilson, E. (2013). What does a lesbian look like? In V. Steele (Ed.), A Queer History of Fashion: From the Closet to the Catwalk (pp. 167-191). New York: Fashion Institute of Technology New York.

Workman, J. E., \& Freeburg, B. W. (2009). Dress and Society. New York: Fairchild Books.

\section{Submit your manuscript to a SpringerOpen ${ }^{\circ}$ journal and benefit from:}

- Convenient online submission

- Rigorous peer review

- Immediate publication on acceptance

- Open access: articles freely available online

- High visibility within the field

- Retaining the copyright to your article

Submit your next manuscript at $\boldsymbol{\nabla}$ springeropen.com 